\title{
REPRESENTAÇõES E APROPRIAÇõES NAS SAGAS FANTÁSTICAS
}

Pedro Afonso Barth ${ }^{1}$

RESUMO: Neste trabalho, pretendemos relacionar os estudos de Chartier com o conceito de saga fantástica. Relacionamos estas e as ideias de Representação e Apropriação desenvolvidas por Chartier. Ao final do trabalho comprovamos que as sagas fantásticas e sua popularidade podem ser relacionadas com os estudos de Roger Chartier e auxiliam na melhor compreensão do fenômeno.

ABSTRACT: In this article, we intend to relate the studies of Chartier with the concept of fantastic saga. We relate the fantastic sagas with representation of concepts and ownership developed by Chartier . At the end of the work we proved that the fantastic sagas and its popularity may be related to the studies of Roger Chartier and assist in better understanding of the phenomenon.

PALAVRAS-CHAVE: Sagas Fantásticas; Apropriação; Representações; Formação de leitores; Roger Chartier.

KEY WORDS: Fantastic sagas; Appropriation; Representations;. Training readers; Roger Chartier.

1 Doutorando na Universidade Estadual de Maringá. Mestre em Letras pela Universidade de Passo Fundo (2016) na Linha de Leitura e Formaçã̃o do Leitor. E-mail do autor: pedrobarth@ hotmail.com 


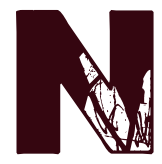
os últimos anos, séries de livros, como O Senhor dos Anéis, Harry Potter, Jogos Vorazes, Instrumentos Mortais, As Crônicas de Gelo e Fogo, Percy Jackson, entre outras, obtiveram grande sucesso de vendas e de repercussão. As obras citadas, além do êxito alcançado entre jovens leitores, possuem várias características em comum, como o fato de mobilizarem aspectos fantásticos, de terem recebido adaptações em várias mídias e de atraírem leitores na internet - tanto na formação de comunidades virtuais quanto na escrita de fanfictions. Por essas características peculiares, tais narrativas podem ser denominadas como sagas fantásticas.

Obras com características de uma saga fantástica vem sendo lançadas no Brasil nos últimos anos. Podemos citar, entre outras, a série Dragões de Éter, de Raphael Draccon (2010), a série Os sete, de André Vianco (2001), O espadachim de carvão, de Affonso Solano(2013), A batalha do apocalipse, de Eduardo Sphor (2012), Sombras do Medo, de Camila Pelegrine (2014).

Sagas são uma importante categoria de análise para a compreensão dos atuais fenômenos de leituras entre os jovens. Portanto, relacionar tal conceito com os estudos do teórico francês Roger Chartier parece amplamente profícuo. Neste artigo, partimos da premissa de que os conceitos desenvolvidos pelo estudioso francês fornecem subsídios para pensarmos nas atuais tendências e fenômenos de leitura como, por exemplo, as sagas fantásticas.

Roger Chartier é, atualmente, um dos maiores expoentes nos estudos sobre a história da leitura e do livro. Sua obra, apesar de fundamentada no campo de estudos da História, é absolutamente transdisciplinar, já que permite um fecundo diálogo com outras áreas do conhecimento, entre elas, os estudos literários. Os estudos de Chartier (1990, 1999) são revolucionários à medida que se distanciam de modelos explicativos reducionistas e deterministas, e ressignificam o conceito do que é cultura, relacionando-o com todas as significações que os homens atribuem à sua realidade, às suas práticas e a si mesmos. A discussão sobre os estudos desenvolvidos por Chartier vem ao encon- 
tro de uma importante reflexão sobre o ensino de literatura no país e de uma nova concepção do papel da leitura. Segundo Castro Rocha (2013, p. 15) "o diálogo sistemático da obra de Roger Chartier com os estudos literários deve continuar e pode transformar-se numa interlocução indispensável em um momento que os professores de literatura precisam, literalmente, reinventar o seu ofício".

Levantamos, nesse trabalho, a seguinte hipótese: os estudos de Roger Chartier podem fornecer uma importante contribuição à compreensão do fenômeno das sagas fantásticas. Portanto, temos o objetivo de relacionar alguns dos conceitos desenvolvidos e estudados por Chartier - especialmente as apropriações e representações - com a recepção e a leitura das sagas. Para tanto, dividiremos o artigo em três seções principais. Primeiramente, abordaremos algumas das contribuições teóricas de Chartier. Na seção seguinte, definiremos as principais características das sagas fantásticas. Por sua vez, nas últimas seções, apontaremos algumas possibilidades de diálogo entre os conceitos desenvolvidos por Chartier com alguns aspectos observados do fenômeno das sagas.

\section{CONTRIBUIÇõES DE CHARTIER PARA A FORMAÇÃo DE LEITORES}

Uma das maiores contribuições de Roger Chartier aos estudos literários foi a de estabelecer a importância da literatura como meio de registrar a história cultural de um povo. Nesta seção, refletiremos sobre os conceitos de representação e de apropriação. Por meio de tais conceitos, Chartier reconfigurou os estudos da história da leitura, pois eles retomam dois elementos fundamentais para a compreensão da circulação de livros: o suporte material dos textos e as variadas formas de ler.

Representação, segundo Chartier (1990, p. 19), o modo de perceber como o mundo social é organizado, são "estes esquemas intelectuais incorporados que criam as figuras graças às quais o presente pode adquirir sentido, o outro tornar-se inteligível e o espaço ser decifrado." 
Dessa maneira, as representações devem ser entendidas como sendo todas as delimitações, categorizações e classificações que organizam a apreensão do funcionamento da sociedade. $O$ estudioso francês considera que é impossível estudar a história cultural sem voltar um olhar crítico para as representações, isso porque, os sujeitos produtores e receptores de cultura circulam entre os polos de práticas e representações. Assim, Chartier (1990) pontua que é fundamental identificar a maneira como, nas práticas, nas representações ou nas produções, cruzam-se e se imbricam diferentes formas culturais.

As representações nunca serão neutras, pois são determinadas por sujeitos e grupos sociais que defendem um modo de vida e os interesses específicos de um grupo. Chartier alerta que, para compreender as diferentes representações, é preciso relacioná-las aos discursos proferidos, contrastando com a posição de quem os profere. Por isso, as obras literárias de uma determinada época e a forma como tais obras são lidas possibilitam verificar diferentes representações, além de perceber a energia social inscrita nos textos. Segundo Chartier (1990), energia social seria o modo pelo qual as forças da sociedade estão codificadas na literatura. Forças que podem fazer tanto a representação de um aspecto cultural de um povo, como representar o passado.

Outro conceito fundamental dentro do quadro teórico de Chartier é o de apropriação. $O$ autor francês retoma uma expressão já anteriormente definida por Michel Foucault (1996) e amplia o seu significado. Foucault utiliza o termo apropriação para descrever o controle sobre a difusão e circulação de discursos. Chartier concorda com esse sentido, mas aponta outra possível dimensão para o termo: seria a forma que indivíduos recepcionam e se apoderam de textos e objetos. O conceito de apropriação de Chartier mescla tanto o controle quanto a invenção, a partir dos quais há a possibilidade da imposição de um sentido único, como também a possibilidade da produção de novos sentidos. Dessa forma, as apropriações devem ser vistas como os diferentes processos através dos quais "é historicamente produzido um sentido e diferenciadamente construída uma significação" (CHARTIER, 1990, p. 24). 
O desenvolvimento do conceito de apropriação permitiu à Chartier comprovar os diferentes usos do objeto cultural livro durante a história. Podemos considerar que toda leitura é sempre uma apropriação, pois há a produção de significados. Chartier (1999) postula que os textos, livros e obras destinadas a configurar pensamentos não são inteiramente eficazes, pois os leitores se apropriam do que leem, e criam seus próprios sentidos. Cada época apresenta uma maneira partilhada e distinta de ler, o que afeta o sentido dos textos e a forma com que foram compreendidos. Assim, a interpretação de um texto em uma determinada época está atrelada às formas nas quais se deu a apropriação do texto, ou seja, apesar da liberdade que o leitor tem de construir sentidos, é importante observar essas limitações.

Com o desenvolvimento do conceito de representação e apropriação, Roger Chartier de certa forma, rompe com uma análise literária tradicional - pautada pelo contato direto do crítico com a obra e ao funcionamento interno do texto - e atribui um maior protagonismo às transformações materiais e às leituras feitas pelos homens de cada época. Chartier (1999) pontua que tais elementos são fundamentais para a construção de sentido e interpretação da leitura em qualquer época. Utiliza como exemplo a recepção da obra Dom Quixote de La Mancha, de Miguel de Cervantes (1547-1616), que era lido em silêncio, como hoje, mas também em voz alta, capítulo por capítulo, para plateias de ouvintes. Ao longo dos séculos, a leitura conheceu várias revoluções: a mudança da literatura oral e da leitura em voz alta para a conquista medieval da leitura silenciosa e visual, o iluminismo e a febre de leitura no século XIX e a entrada de novos agentes leitores: mulheres, crianças e classes menos favorecidas.

Atualmente, presenciamos outra revolução na leitura provocada pela internet, pelo livro eletrônico e pelo hipertexto. Sobre isso, Chartier pontua que "a revolução do livro eletrônico é uma revolução nas estruturas do suporte material do escrito assim como nas maneiras de ler" (1999, p. 13). A internet permite novas maneiras de apropriações de leituras, além de possibilitar a formação de novas formas de comu- 
nidades de leitores. As representações inscritas nos textos e a energia social também são reconfiguradas nesse panorama. Isso ocorre, pois, segundo Chartier, o computador não é apenas um novo veículo para imagens ou jogos, mas ele é responsável também pela multiplicação da presença do escritor nas sociedades contemporâneas.

Houve por muito tempo uma grande desconfiança dos efeitos do computador e da internet nos processos de leitura, da parte da escola. Chartier é um crítico dessa desconfiança, pois é um defensor das possibilidades educativas que podem advir das novas tecnologias e das diversas experiências para alfabetização ou pela transmissão do saber à distância. Em uma entrevista para a jornalista Isabel Lustosa, em 2004, Chartier afirmou:

De fato, é preciso dar aos usuários da internet instrumentos críticos para entender como os textos foram construídos, para avaliar o grau de seriedade de cada local. Não podemos minimizar o significado da ruptura de um mundo onde objetos e textos estão vinculados através de materialidades múltiplas com um mundo em que a mesma superfície iluminada do monitor dá a ler todos os gêneros textuais. A reflexão sobre essas transformações muda a percepção dos textos e de suas diferenças (LUSTOSA, 2004).

As novas mídias e linguagens criaram novas formas de apropriação de textos e narrativas, porém, nem todos os leitores são competentes o suficiente para ler e compreender de forma crítica nessa nova realidade. Por essa razão, a escola precisa preocupar-se com a construção de um ensino voltado a todas as formas de leitura e apropriação.

A esse artigo interessa pontuar outro aspecto abordado por Chartier em seus estudos: as comunidades de leitores. Ele conceituou comunidade de leitores como "aquelas comunidades interpretativas, cujos membros compartilham os mesmos estilos de leitura e as mesmas estratégias de interpretação". (1994, p. 216). As comunidades podem ser compostas por indivíduos de uma mesma classe social ou profissão, 
ou que moram na mesma localidade ou tem os mesmo interesses e aspirações. Tal proximidade faz com que esse agrupamento tenha uma apropriação de leitura muito semelhante. Chartier afirma que, apesar de fazer parte de uma comunidade, os sujeitos ainda preservam a sua individualidade e assim torna-se possível que um indivíduo participe de mais de uma comunidade de leitores.

A tecnologia, as redes sociais e as novas mídias multiplicaram as possibilidades de formação de comunidades de leitores. Dessa maneira, temos comunidades em redes sociais, em blogs, páginas específicas, entre outras. Quando uma comunidade de leitores é construída por jovens, não há apenas a socialização do gosto literário, mas também de gostos, práticas e expressões.

\section{AS SAGAS FANTÁSTICAS}

Nesta seção, apresentaremos as principais características de uma saga fantástica. No Brasil, os estudos sobre sagas são escassos, diferente da Espanha, em que autores como Alberto Martos García (2009, 2010), Eloy Martos Núñez (2007) e Glória Garcia Rivera (2004) dedicam-se ao estudo do papel das sagas fantásticas, tanto da sua estrutura narrativa quanto em relação à formação de leitores. Uma saga é composta por um universo criado e autoconsciente, reproduzido em diversas linguagens - escrita, audiovisual, cartográfica - e faz uso de recursos visuais. O conceito de saga é muito profícuo para compreender a relação entre mercado, leitores e obra na consolidação do sucesso de séries literárias, e essa é uma reflexão fundamental para pensar a formação de leitores no século XXI.

Sagas são constituídas de uma interessante hibridação - mitos e elementos da tradição oral são resgatados e reconfigurados com os valores contemporâneos, ao mesmo tempo em que a mesma história é contada por diferentes linguagens. Martos García (2009) utiliza o conceito de paracosmos para explicar essa criação de um universo alternativo que é dotado de regras próprias. 
Segundo Garcia Rivera (2004), paracosmos é um conceito originário da psicologia e faz referência a um tipo de fantasia infantil que se caracteriza pela criação de um mundo paralelo pela criança, um mundo próprio em que se pode brincar, jogar, desenhar, fabular. Os autores espanhóis ressignificam esse termo para explicar o mundo próprio, com regras delimitadas que é criado por uma saga. Por sua vez, tais regras de funcionamento do paracosmos são denominadas por Martos Garcia (2011) como sendo arquitextos. Por exemplo, no caso da saga Harry Potter, o arquitexto principal é a mitologia que envolve a bruxaria desde a idade média. Já a saga Piratas do Caribe, iniciada no cinema, utiliza como base o imaginário que existe em volta da figura dos piratas. Martos García (2009) aponta que as regras do paracosmos em cada ficção não são explícitas nos primeiros momentos de uma leitura. Os padrões se configuram à medida que o leitor conhece o universo da saga e emergem os protótipos, os arquitextos e diferentes repertórios de coisas e eventos que povoam esse mundo.

O paracosmos de uma saga não se limita a um livro, mas se estende para continuações; além disso, ultrapassa a linguagem escrita e abarca diferentes linguagens, como as dos filmes, dos seriados, dos mapas, dos games, entre outras (RIVERA, 2013). Assim, um livro pode dar origem a um universo que será expandido em outras plataformas e, muitas vezes, por autores diferentes. Estruturalmente, as sagas também têm como característica a contínua expansão: são histórias sem fim, pois não se resumem a um livro e até podem ser representadas e adaptadas em vários meios concomitantemente. A aceitação do mercado, obviamente, acaba sendo a principal razão para a expansão de uma saga, pois somente as histórias que rendem lucros e público recebem investimentos e possuem assim uma grande longevidade. Um exemplo recente é a saga Star Wars, que por possuir um grande público tem recebido grandes expansões em sua narrativa, tanto em formato de filmes, como em outras mídias e produtos.

O leitor de sagas consome livros e filmes concretos, mas tem necessidade de ligar-se a uma série, a um ciclo ou coleção mais ampla, o que 
propicia uma leitura extensiva e multimidial. Dessa forma, o leitor de sagas fantásticas transita com muita facilidade por diferentes linguagens e meios semióticos (NúÑEZ, 2007).

Martos Núñez (2007) afirma que a narração serial e a possibilidade de leitura não linear são inerentes às sagas modernas. A partir de um tronco inicial, a história se desdobra e podem se desenvolver múltiplos itinerários narrativos, que possuem como elo comum o fato de acontecerem no mesmo mundo. Garcia Rivera (2004) pontua que o que constitui uma saga é o fato de compartilhar um universo comum e não o de contar uma história linear. Assim, uma saga é um modelo aberto de relato, extenso, propenso a modos distintos de leitura, suscetível a ampliações - na criação de enciclopédias, de histórias prequelas e continuações.

\section{APROXIMANDO SAGAS FANTÁSTICAS DOS CONCEITOS DE CHARTIER}

Nesta seção, relacionaremos os conceitos de Chartier com o fenômeno das sagas fantásticas. Vamos refletir especialmente sobre quatro questões: a) as representações que existem nas sagas fantásticas; b) a forma que os leitores de uma saga se apropriam de suas leituras; c) a maneira com que comunidades de leitores se articulam em torno das sagas fantásticas; e finalmente; d) refletiremos sobre as sagas como leituras selvagens e como elas podem servir à escola como uma ponte para outras leituras. Nas exemplificações citaremos sagas famosas de autores estrangeiros, como as Crônicas de Gelo e Fogo/Guerra dos Tronos (2010), de George Martin e também sagas escritas por brasileiros, como por exemplo, Sombras do Medo (2015), de Camila Pelegrine.

A grande maioria das sagas apresenta a fantasia e a magia como elementos de protagonismo. Dessa forma, as histórias costumam ser ambientadas em mundos inventados permeados pelo insólito e elementos místicos. Apesar disso, não podemos considerar que são criações escapistas, que não tem relação com o mundo real e contemporâneo dos leitores. Como pontua Martos Garcia (2009), não é possível fabu- 
lar sem estabelecer relações com o mundo real. Portanto, as sagas fantásticas apresentam representações de grupos sociais e diferentes energias sociais.

Podemos exemplificar tal relação com a saga Sombras do Medo, de Camila Pelegrine. A narrativa é ambientada em um mundo distópico: nosso planeta no futuro está devastado devido a guerras humanas e desastres naturais. Esse mundo é dividido em cinco grandes regiões. Em cada uma delas vivem ordinários, indivíduos que tentam sobreviver em condições miseráveis, e singulares, que são a elite dominante. A narrativa acontece em torno da personagem Anabele, uma jovem ordinária que terá de enfrentar terríveis forças malignas que tentaram devorar a alma dos humanos que restaram, ao mesmo tempo que se envolve em um triângulo amoroso.

Nestas poucas linhas já fica claro que o mundo criado por Camila Pelegrine é uma distopia que reproduz um mundo devastado pelo aquecimento global. A obra é uma representação de um alerta, um medo coletivo que na obra de ficção é confirmado. A metáfora proposta pela saga pode não primar pela originalidade, mas há uma inegável ancoragem na realidade.

Conforme Chartier (1990), todo texto, seja ele literário ou de qualquer outro tipo, é uma representação do real que se apreende e não se pode desligar de sua realidade de texto construído pautado em regras próprias de produção inerentes a cada gênero de escrita. Observamos isso nas sagas, pois apesar da ambientação em um mundo criado, com elementos místicos e insólitos, há sempre a possibilidade de perceber o mundo contemporâneo refletido nele. Representações da sociedade atual ficam marcadas na narrativa ou no modo como ela será lida e interpretada. Martos García (2011, p. 18) relaciona a necessidade de inventar mundos novos para entender melhor a nossa realidade, pois traçar mundos, mapas, rios, raças, cronologias e dar a tudo isso um sentido finalista - o que precisamente conduz a história a um fim - relaciona-se à necessidade ancestral de criar histórias para falar também do que realmente não acontece, mas poderia 
ser imaginado como outros mundos possíveis. 'Invento outros mundos para entender este', Isaac Asimov explicou-o de forma rotunda, quando dizia que a ciência de ficção só aparentemente tratava de marcianos, robôs ou espadas laser: seu verdadeiro objeto era falar à humanidade das mudanças que estavam em processo.

Dessa forma toda saga apresenta representações de energias sociais identificáveis no mundo contemporâneo, mas talvez apenas os leitores atentos e críticos possam estabelecer tal relação. No caso da saga citada, Sombras do Medo, uma leitura crítica é capaz de perceber que a narrativa é uma distopia sobre um mundo dilacerado pela opressão, apresenta uma contundente crítica ao mundo globalizado que cultua realities shows, além de outros aspectos. Entretanto, leituras menos profundas são possíveis, como a de perceber a história como sendo apenas uma história de um triângulo amoroso em um mundo atribulado. A leitura da saga dependerá das apropriações feitas pelos leitores.

Uma das principais características dos leitores de uma saga fantástica é a sua tendência a tornar-se fã de um universo. Por isso, a escolha de uma saga nunca é aleatória, pois o leitor apenas se tornará fão caso houver a possibilidade de se identificar com os elementos do paracosmos. Uma vez identificado com os arquitextos e regras do mundo, ele pode tornar-se fã e colaborador da expansão do paracosmos, produzindo histórias, fanfictions ou simplesmente consumindo a grande gama de produtos de sua saga favorita. Ou seja, o leitor de uma saga apresenta uma forma ativa de apropriação. Martos Garcia (2009) aponta que essa forma de apropriação, na maioria das vezes, não ocorre pela mediação da escola ou indução acadêmica ou literária e sim por trocas feitas entre os próprios adolescentes, principalmente na internet.

Porém, não podemos afirmar que esse comportamento é novo; pelo contrário, observa-se a existência de leitores/fãs desde o surgimento de fanzines, distribuídos nos corredores de escolas. Fanzine é uma abreviação de fanatic magazine, um tipo de publicação despre- 
tensiosa feita por fãs de determinado tipo de temática, como fantasia, ficção científica, videogames etc. A diferença é que vivemos um momento em que a internet possibilitou que mais pessoas tivessem acesso ao papel de produtores, de criadores. Qualquer pessoa dispõe de meios para criar enredos baseados em seus personagens favoritos ou colaborar com enciclopédias virtuais sobre o universo que admira. Esse fenômeno é definido por Jenkins (2009, p. 8) como cultura de convergência, "onde as velhas e as novas mídias colidem, onde mídia corporativa e mídia alternativa se cruzam, onde o poder do produtor de mídia e o poder do consumidor interagem de maneiras imprevisíveis".

Martos García (2009) utiliza o termo ficción mania para caracterizar a tendência dos leitores em se apropriar de narrativas com o comportamento de fãs. Tal comportamento é um reflexo de nossa época, é uma das formas contemporâneas de apropriação de textos. Como pontua Chartier (1996, p.20) "cada leitor, a partir de suas próprias referências, individuais ou sociais, históricas ou existenciais, dá um sentido mais ou menos singular, mais ou menos partilhado, aos textos de que se apropria". E as sagas fantásticas parecem ser narrativas que conduzem a um modo coletivo de apropriação.

Em relação às sagas fantásticas e à sua recepção, podemos destacar que a cultura de convergência possibilitou a criação de espaços virtuais de discussão sobre os mundos criados adorados por fãs, leitores e telespectadores. Estas são exemplos de comunidades de leitores (CHARTIER, 1994). Tais espaços são formados por indivíduos que discutem, dialogam e agem de maneira cooperativa; assim, são capazes de entender o paracosmos de uma saga de maneira que não fariam de forma individual.

Os sites e comunidades virtuais permitem que o leitor de sagas satisfaça a uma necessidade humana: compartilhar leituras. Como relata Petit (2008), ao compartilhar a leitura, os leitores, efetivamente, experimentam um sentimento de pertencimento: a sensação de pertencer 
a alguma coisa, seja a um grupo específico ou a humanidade como um todo, seja do nosso tempo ou de tempos passados. A leitura - seja de livros, de séries, de quadrinhos -, segundo a antropóloga francesa, possibilita uma abertura para o outro e, assim, "o mais íntimo pode alcançar neste ato o mais universal” (PETIT, 2008, p. 43).

Ideias convergentes às de Jenkins (2009) quando aponta que a experiência de compartilhar e comparar informações, opiniões e recursos sobre uma narrativa midiática pode garantir maior profundidade de envolvimento dos espectadores/leitores, pois a convergência dos meios de comunicação impacta o modo como esses meios são consumidos. Um exemplo do papel da internet na formação de comunidades de leitores e na criação de espaços de discussões de leituras é o caso da saga As Crônicas de Gelo e Fogo, do autor norte-americano George R. R. Martin. Sobre o papel da internet e dos grupos virtuais, Whitehead (2015, p. 70) afirma que

os fãs se reúnem em blogs e fóruns para debater as questões levantadas em cada novo lançamento, seja a origem de John Snow, as hipóteses para a imprevisibilidade das estações ou as motivações dos Outros. Discussões desse tipo - ainda que algumas vezes muito acaloradas- aumentam o compromisso dos leitores com a história, dando-lhes oportunidade de contribuir ativamente. Isso ajuda a criar e manter um grupo de fãs leais e entusiasmados, e fornece um vasto material para eles discutirem enquanto esperam o próximo livro.

A citação faz referência a blogs de leitores dos livros, mas também há blogs e comunidades específicas sobre games, seriado, quadrinhos e outros produtos decorrentes do mundo criado por George R. R. Martin. Conforme Diana Corso e Mário Corso (2011, p. 22), "certos fãs estacionam sua alma em um universo mágico ou ficcional, na relação com uma personagem, e se conectam preferencialmente entre quem tem a mesma dedicação para cultuar a obra e o autor." Os leitores de uma saga - bem como leitores e fãs de obras de ficção de maneira 
geral - buscam uma identidade de grupo, ou seja, buscam esferas de coletividade. E encontram isso nas comunidades de leitura citadas por Chartier.

\section{SAGAS FANTÁSTICAS COMO LEITURAS SELVAGENS}

Apesar das sagas fantásticas possuírem o formato impresso, na internet e nas redes sociais circulam textos, adaptações, discussões que aprofundam e expandem o universo da saga. Talvez, sem a internet, certas sagas não conquistariam tanta popularidade. Por essa razão, podemos apontar a leitura eletrônica como uma poderosa incentivadora da ascensão das sagas. Talvez por essa dependência do meio eletrônico e da forte vinculação com os best-sellers, muitas vezes as sagas fantásticas são desprezadas enquanto produtos culturais. Nesse sentido, sagas fariam parte do que Chartier (1999) denomina como leituras selvagens, leituras que são feitas à revelia da escola e muitas vezes apresentam pouca legitimidade cultural.

Martos García (2009) aponta que sagas fantásticas, geralmente, sofrem grandes depreciações críticas de professores, estudiosos e escolas. A condenação acontece ancorada na acusação de que as sagas são histórias pouco profundas devido aos enredos irreais e fantásticos. 0 autor concorda que, de certa maneira, é possível, sim, que sagas permitam leituras escapistas. Entretanto, isso não deve ser visto como um problema; pelo contrário, a evasão pode chegar a ser expressão da verdade profunda do mito. Ou seja, a fantasia de uma saga dialoga com a mitologia humana como um todo, com a necessidade da fantasia que constitui a natureza humana. Além disso, como citamos anteriormente, toda saga fantástica traz representações da realidade e permite várias gradações de leitura.

Chartier apresenta uma reflexão semelhante, pois, para o autor, as leituras selvagens não devem ser condenadas e proibidas. Pelo contrário, devem ser sim aproveitadas pela escola já que "é preciso utilizar aquilo que a norma escolar rejeita como um suporte para dar acesso 
à leitura na sua plenitude, isto é, ao encontro de textos densos e mais capazes de transformar a visão de mundo, as maneiras de sentir e de pensar" (CHARTIER, 1999, p. 51).

No presente artigo comprovamos que os estudos de Chartier fornecem subsídios teóricos que auxiliam na compreensão das sagas fantásticas enquanto leituras autênticas de jovens e leitores em formação. Leituras que devem ser valorizadas pela escola e pelas instituições preocupadas com a formação de leitores. Somente compreendendo a influência dessas leituras nos horizontes da subjetividade dos leitores será possível dialogar e incentivar a leitura de outras obras e autores.

\section{REFERÊNCIAS BIBLIOGRÁFICAS}

CHARTIER, Roger. A aventura do livro: do leitor ao navegador; tradução Reginaldo de Moraes. São Paulo : UNESP/IMESP, 1999.

. Práticas de leitura. São Paulo: Estação Liberdade, 1996.

. A ordem dos livros. Brasília: UNB, 1994.

. A história cultural: entre práticas e representações. Tradução de Maria Manuela Galhardo. Lisboa: Difel, 1990.

CORSO, Diana Lichtenstein; CORSO, Mário. A psicanálise na Terra do Nunca: ensaios sobre a fantasia. Porto Alegre: Penso, 2011.

FOUCAULT, Michel. A ordem do discurso. São Paulo, Loyola, 1996.

GARCIA RIVERA, Glória. Paracosmos: las regiones de la imaginación (los mundos imaginarios en los géneros de Fantasía, Ciencia Ficción y Horror: nuevos conceptos y métodos). Primeras noticias. Revista de literatura, n. 207, 2004 p. 61-70.

JENKINS, Henry. Cultura da convergência. São Paulo: Aleph, 2009. LUSTOSA, Isabel. Conversa com Roger Chartier. Disponível em: http:// observatorio daimprensa.com.br/diretorio-academico/conversa-com-roger-chartier/ Acesso em: 05 Jan. 2016.

MARTIN, George R. R. A Guerra dos Tronos: As crônicas de gelo e fogo. Tradução de Jorge Candeias. São Paulo: Leya, 2010 
MARTOS NÚÑEZ, Eloy. Hipertexto, cultura midiática e literaturas populares: $O$ auge das sagas fantásticas. In: RETTENMAIER, Miguel; RÖSING, Tania Mariza Kuchenbecker (Coord.). Questões de leitura no hipertexto. Passo Fundo: Ed. Universidade de Passo Fundo, 2007. p. 50-63.

MARTOS GARCIA, Alberto. Introducción al mundo de las sagas. Badajoz: Universidade de Extremadura, 2009

. Os jovens diante das telas: novos conteúdos e novas linguagens para a educação literária. In: RETTENMAIER, Miguel; RÖSING, Tania Mariza Kuchenbecker (Coord.). Questões de literatura na tela. Passo Fundo: Ed. Universidade de Passo Fundo, 2011. p.13-36.

PELEGRINE, Camila. Sombras do Medo. São Paulo: Arwen, 2015.

PETIT, Michèle. Os Jovens e a leitura. São Paulo: Editora 34, 2008.

ROCHA, João Cezar de Castro (Coord.). Roger Chartier: a força das representações: história e ficção. Chapecó: Argos, 2013. 291 p.

WHITEHEAD, Adam. Um mundo incerto: história e contagem de tempo em Westeros. In: LOWDER, James (Org.). Além da Muralha: explorando o universo de As Crônicas de Gelo e Fogo de George R. R. Martin. Tradução Márcia Blasques. São Paulo: Leya, 2015. p. 61-70. 